\title{
Phytotherapy an alternative way of treating diseases on scientific basis
}

Mumtaz M. Mazicioğlu

Erciyes University, Faculty of Medicine,

Department of Family Medicine, Kayseri, Turkey

\section{Fitoterapija alternativni način lečenja bolesti na naučnoj osnovi}

Mumtaz M. Mazicioğlu

Erciyes univerzitet, Medicinski fakultet,

Katedra porodične medicine Kajseri, Turska

\section{Abstract}

Plants are one of the main sources of nutrition, cosmetics, and medical supplements and drugs. Certain characteristics of plants make them suitable for phytotherapeutic use: easy to access, low cost, and the common perception that they are natural and safe. Although conventional medical therapies have a reliable scientific basis and widespread use, there are several countries, from different socioeconomic levels, where the use of plant-based remedies is legally regulated. Traditional complementary and alternative therapeutic methods (TCAM) or remedy use is prevalent in both acute and chronic health conditions, in about one-third and two-thirds of cases, respectively. Additionally, about one-third of individuals who use phytotherapeutics do not inform their physicians about it. Phytotherapy is the most frequently used TCAM method.

If plant secondary metabolites - phenols, polyphenols, tannins and flavonoids, glycosides, terpenes, triterpenoids and saponins, essential oils and resins, fixed oils and alkamides, polysaccharides, alkaloids are used in certain doses for a particular duration of time to counteract certain metabolic processes, we may describe the process as conventional medical practice. On the other hand, plants are also used as remedies in TCAM procedures, according to humoral pathology theory; the contemporary medical method used until the 18 th century. Still, we can not describe the process as a conventional medical method because phytochemicals are used to intervene in certain metabolic processes in order to rebalance the humoral disorder and certain elements may repair the disbalance that leads to disease.

Keywords: Phytotherapy, traditional complementary and alternative medicine, conventional medicine, secondary metabolites.

\section{Sažetak}

Biljke su jedan od glavnih izvora hrane. Koriste se $\mathrm{u}$ kozmetici kao medicinski suplementi i lekovi. Neke osobine čine ih podobnim za upotrebu kao fitoterapeutici: dostupne su, jeftine, a i ustaljeno je mišljenje da su prirodne i bezbedne. Iako konvencionalni lekovi imaju pouzdanu naučnu osnovu i široku primenu, ima i zemalja, različite socioekonomske razvijenosti, u kojima je upotreba biljnih lekova zakonom regulisana. Upotreba tradicionalnih alternativnih metoda ili lekova zastupljena je u lečenju i akutnih i hroničnih bolesti (trećina akutnih i dve trećine hroničnih oboljenja). Osim toga, jedna trećina ljudi koji koriste biljne preparate ne obaveštavaju svoje lekare o tome. Fitoterapeutici su najzastupljeniji metod alternativne medicine.

Ako se sekundarni metaboliti biljaka - fenoli, polifenoli, tanini i flavonoidi, glikozidi, terpeni, triterpenoidi i saponini, esencijalna ulja i smole, fiksna ulja i alkamidi, polisaharidi, alkaloidi koriste u određenoj dozi, određeno vreme, kako bi sprečili izvesne metaboličke procese, može sereći da ovaj proces odgovara onom u konvencionalnoj medicinskoj praksi. S druge strane, biljke se često koriste kao lekovi u alternativnoj medicini, u skladu sa teorijom humoralne patologije. Bio je to konvencionalni medicinski metod do 18. veka. Ipak ne možemo opisati ovaj proces kao konvecionalni medicinski metod jer se fitohemikalije koriste kako bi sprečile neke metaboličke procese i rebalansirao humoralni poremećaj, a neki od njih mogu popraviti poremećaj koji je doveo do bolesti.

Ključne reči: fitoterapija, tradicionalna alternativna medicina, konvencionalna medicina, sekundarni metaboliti. 


\section{Phytotherapy}

Can phytotherapeutics be used in GP's everyday practice? Which ones we most frequently use in Turkey and recommend to our patients either as medications or together with conventional medications?. Which ones are available and widely known?

Phytotherapy is a widespread intervention. Use of natural products, primarily plants, is a frequent habit of many people. They either use them on their own or they are prescribed by physicians or other he professionals ${ }^{1,2}$. The constitutes of medicinal plants; An introduction to the chemistry and therapeutics of herbal medicine. Second Ed. Singapore 2004; pp 1-13. Formal medical education provides information only about conventional drug therapy, surgery, nonsurgical interventions e.t.c. Use of phytotherapy in medical practice, as a tool, to both strengthen body health or as a medical therapy is scarce ${ }^{3}$. It may not be wise to expect medical doctors to prescribe phytotherapeutic remedies since they are neither educated nor given continuous medical education on the subject. On the other hand, phytotherapy is an option, completely or partially paid by health insurance or an unpaid option, depending on the country`s health politics. In daily practice, whatever the health politics is or whoever is prescribing them, it concerns healthy and ill people, just the same. People, healthy or ill, frequently use phytotherapy for many purposes, whether it is prescribed by a health professional or not ${ }^{4}$.

Use of phytotherapeutic remedies, as a tool of conventional medical practice or complementary and alternative medicine (CAM) practice, is not so easy. By definition CAM has a specific method of explaining the cause of medical disorders and their therapeutic process ${ }^{5,6}$.There are various reports about the validity and reliability of CAM methods in therapeutic purposes ${ }^{7}$. Current literature provides a great amount of knowledge on plants, but it may not be easy to interpret this information in the context of well-being, health improvement, diagnosis, therapy and rehabilitation by a single professional, such as a medical doctor or a pharmacist.

Historical background on using plants for healthy living and unhealthy conditions can be dated to ancient Egypt and Mesopotamia. Plants, animals and minerals may be regarded as the too easily used remedies for certain conditions. A few hundreds of them are described in ancient texts, dated back to more than 2000 years ago ${ }^{8}$.

\section{Phytotherapy in conventional medical practice}

Plant chemicals are produced in photosynthesis and glycolysis process, to primarily metabolize carbohydrates or proteins, and then they are converted into secondary metabolites ${ }^{9}$.

\section{Fitoterapija}

Možemo li u svakodnevnoj medicinskoj praksi lekara opšte medicine koristiti fitoterapiju? Koje biljne preparate mi u Turskoj najčešće preporučujemo svojim pacijentima, uz ili umesto medikamentne terapije? Koji fitopreparati su dostupni i široko poznati stanovništvu?

Fitoterapija se široko primenjuje. Ljudi često koriste prirodne proizvode, pre svega biljke, Koriste ih ili po sopstvenom nahođenju ili po preporuci lekara i drugih zdravstvenih profesionalaca ${ }^{1,2}$. Formalno medicinsko obrazovanje daje nam informacije samo o konvencionalnim lekovima, hirurškim, nehirurškim intervencijama i sl. Upotreba fitoterapije u medicinskoj praksi, kao alata za jačanje zdravlja ili medicinske terapije je retka ${ }^{\ddagger}$. Možda nije realno očekivati od lekara da propisuju fitoterapijske lekove, jer niti su obučeni niti se i sada obučavaju o njima. S druge strane, fitoterapija jeste mogućnost, koju u nekim zemljama potpuno ili delimično pokriva zdravstveno osiguranje, a u nekima ne pokriva uopšte, što zavisi od zdravstvene politike zemlje. U svakodnevnoj praksi, bez obzira kakva je zdravstvena politika, ili ko propisuje fitoterapeutike, oni podjednako utiču i na zdrave i na bolesne. Bilo da su zdravi ili bolesni, ljudi često koriste fitoterapiju u različite svrhe, bez obzira da li ju je propisao zdravstveni radnik ili ne ${ }^{4}$.

Upotreba fitoterapijskih lekova, kao sredstvo zvanične ili alternativne medicine nije lako. Po definiciji, alternativna medicina ima specifično objašnjenje za medicinske probleme i njihovo lečenje $\mathrm{e}^{5,6}$. Postoje mnogi radovi o validnosti i pouzdanosti alternativnih metoda $u$ terapijske svrhe ${ }^{7}$. Savremena literatura nam daje dosta podataka o biljkama, ali nije lako tumačiti ove informacije u kontekstu dobrobiti, poboljšanja zdravlja, dijagnoze, terapije i rehabilitacije od strane profesionalaca, kao što su lekar ili farmaceut.

Istorijski podaci o upotrebi biljaka u svrhu zdravog načina života ili kod bolesti, mogu se naći još u starom Egiptu i Mesopotamiji. Biljke, životinje i minerali mogu se smatrati lekovima koji se olako upotrebljavaju u lečenju određenih stanja. Stotine njih opisani su u starim tekstovima koji datiraju od pre 2000 godina ${ }^{8}$.

\section{Fitoterapija u savremenoj medicinskoj praksi}

Biljne hemikalije nastaju kao proizvod procesa fotosinteze i glikolize, pre svega da metabolišu ugljene hidrate ili proteine, a zatm se pretvaraju u sekundarne metabolite? . 
These secondary metabolites can be listed as ${ }^{9}$ :

- Phenols

- Polyphenols - tannins and flavonoids

- Glycosides

- Terpens

- Triterpenoids and saponins

- Essential oils and resins

- Fixed oils and alkamides

- Polysaccarides

- Alkaloids

Phenols are aromatic alcohols whose hydroxyl group is attached to a benzene ring and their metabolic effects are grouped as bactericidal, antiseptic and anthelmintic. Tannins constitute the largest group of polyphenols and are primarily found in bark of trees or insect galls and their metabolic effect can be described as astringent. Tanniis may protect mucous membranes, reduce inflammation. Flavonoids are yellow and white plant pigments functioning as UV protectors, but they also protect against radiation damage. They are also antioxidants, enzyme inhibitors and light-absorbed screening pigments.

Glycosides are compounds constituted of sugar and non-sugar chemicals. They carry the non sugar chemical to intestinal flora where it acts, depending on the character of insular chemical, as expectorant, sedative, cytotoxic substance or it may have antitussive, immunosuppressive effects etc. Terpens are plant chemicals that are produced via mevalonic acid pathway and their wide range of metabolic effects include anti-inflammatory, sedative, antipyretic, antispasmodic, local anaesthetic, antibacterial, antifungal, antimicrobial, antiprotozoal, vasodilatory, antihypertensive, bronchodilatory, and positive inotropic action. Terpens' therapeutic action depends on their isoprene units (monoterpenes, diterpens, triterpens etc.).

Essential oils are the source of plant aromas and although they constitute a very small percentage of plants and are found as a mixture of other chemicals, they have the potency to be used as drugs. According to their chemical properties essential oils are anti-inflammatory, antiseptic, antiviral, immune stimulators, tonifiers, carminatives, sedatives, mucolytics, spasmolytics etc.

Fixed oils in plants, which are composed of fatty acids, hydrocarbon chains, have metabolic effects on cardiovascular, autoimmune system. They are used as constitutional chemicals in nervous system and play an important role in cholesterol metabolism and inflammatory processes (like omega 3 and 6 fatty acids). Alkamides, composed of carboxylic acids and amines, have analgesic, anti- inflammatory effects. Their insect repellent activity in plants corresponds with their sialagogue activity in human. Polysaccharides are a large group of chemicals which take part in food storage, cellular membrane protection and keep cell wall rigid. Their

\section{Sekundarni metaboliti su9: \\ - Fenoli \\ - Polifenoli - tanini i flavonoidi \\ - Glikozidi \\ - Terpeni \\ - Triterpenoidi i saponini \\ - Esencijalna ulja i smole \\ - Fiksna ulja i alkamidi \\ - Polisaharidi \\ - Alkaloidi}

Fenoli su aromatični alkoholi čija je hidroksilna grupa vezana za benzenski prsten i njihovi metabolički efekti su baktericidni, antiseptički i antihelmitični. Tanini predtavljaju najveću grupu polifenola i primarno se sreću u kori drveća ili larvama insekata i njihov metabolički efekat se može opisati kao astringentni. Tanini mogu da štite mukozne membrane, smanje inflamaciju. Flavonoidi su žuti ili beli biljni pigmenti koji pružaju UV zažtitu, ali takođe štite od štetnog zračenja. Oni su takođe i antioksidansi, inhibitori enzima i zaštita od apsorpcije svetla.

Glikozidi su jedinjenja koja se sastoje od šećernih i nešećernih hemikalija. Oni prenose nešećernu hemikaliju do crevne flore, gde ova deluje zavisno od karakteristika same hemikalije kao ekspektorans, sedativ, citotoksična supstancija ili može imati antitusični, imunosupresivni efekat itd. Terpeni su biljne hemikalije koje se proizvode kroz put mevalonične kiseline i njihov širok spektar metaboličkih efekata uključuje antiinflamatorni, sedativni, antipiretički, spazmolitički, lokalno anestetički, antibakterijski, antifungalni, antimikrobni, antiprotozoalni, vazodilatatorni, anihipertenzivni, bronhodilatatorni, i imaju pozitivno inotropno delovanje. Terapijsko dejstvo terpena zavisi od njihovih izoprenih jedinica (monoterpeni, diterpeni, triterpeni itd).

Esencijalna ulja su izvor biljnih aroma i mada čine mali procenat biljaka i sreću se kao mikstura drugih hemikalija, imaju potencijal da se koriste kao lekovi. U skladu sa njihovim hemijskim osobinama esencijalna ulja mogu imati sledeća dejstva: antiinflamatorno, antiseptičko, antivirusno, imunostimulatorno, tonizirajuće, antiflatulentno, sedativno, mukolitičko, spazmolitičko itd.

Fiksna ulja iz biljaka koja se sastoje od masnih kiselina, hidrokarbonskih lanaca, imaju metaboličke efekte na kardiovaskularni, autoimuni sistem. Koriste se kao gradivne hemikalije u nervnom sistemu i imaju značajnu ulogu u metabolizmu holesterola i inflamatornim procesima (kao omega 3 i 6 masne kiseline). Alkamidi, koji su sastavljeni od karboksilnih kiselina i amina, imaju analgetički i antiinflamatorni efekat. Njihova sposobnost da štite biljke od insekata ima veze sa njihovim sijalogognom (pospešuju produkciju pljuvačke) aktivnošću kod ljudi. Polisaharidi su velika grupa hemijskih supstanci koje imaju ulogu u čuvanju hrane, zaštiti čelijske membrane i očuvanju čvrstine ćelijskog zida. Njihov ublažu- 
demulcent, emollient and mucilage effects are well known. Additionally, antitumour, anti-inflammatory, bactericidal and immunomodulatory effects can be related to certain polysaccharides. Nitrogen containing phytochemicals, such as alkaloids are the last group to be mentioned and they have significant metabolic effects. They are prevalent in Fabaceae, Liliaceae, Ranunculaceae, Apocynaceae, Solanaceae and Papaveraceae families. Their metabolic activities can be grouped as stimulants of central nervous system, expectorant bronchodilators, anticholinergics, antimalarics, bronchodilators ${ }^{10}$.

The major problem, using plants as remedies, is difficulty in dose adjustment. Several factors may interfere with the chemical content of herbs, other than extraction and reparation procedures. These factors may be listed as:

- Even the same plant, cultivated in the same location, may have different quantity of required phytochemical,

- Even the same plant, cultivated in different locations, may have different quantity of required phytochemical,

- Existence of several phytochemicals in the same plant may lead to undesired consequnces when they act together with the remedium cardinale,

- Not every part of a plant may contain the required phytochemical (Table 1),

- Not any part of a plant may contain the required phytochemical since the required phytochemical may not be produced until a specific period of growth (volatile oils can be extracted in the early periods of flowering and after that period they are lost gradually).

Some herbs are easily found in our environment in European region. jući, omekšavajući i mukozni efekat je nadaleko poznat. Neki polisaharidi mogu imati i antitumorski, antiinflamatorni, baktericidni i imunomodulatorni efekat. Fitohemikalije koje sadrže azot, kao što su alkaloidi, poslednja su grupa koju ćemo pomenuti i oni imaju značajne metaboličke efekte. Najčešće se sreću u Fabaceae, Liliaceae, Ranunculaceae, Apocynaceae, Solanaceae i Papaveraceae familijama. Njihive metaboličke aktivnosti obuhvataju stimulaciju centralnog nervnog sistema, ekspektoraciju, antiholinergičko dejstvo, antimalaričko, bronhodilatatorno itd ${ }^{10}$.

Najveći problem u korišćenju biljaka, kao lekova, je to što je teško prilagoditi dozu. Nekoliko faktora može uticati na sadržaj hemikalija u biljkama, osim samog procesa ekstrakcije i reparacije. Ti faktori su:

- C Čak i ista biljka, uzgajana na istoj lokaciji, može imati različite količine tražene hemikalije

- Čak i ista biljka, uzgajana na različitoj lokaciji, može imati različite količine tražene hemikalije

- Postojanje nekoliko fitohemikalija u istoj biljci može dovesti do neželjenih posledica kada deluju zajedno sa remedium cardinale

- Svaki deo biljke ne mora sadržati određenu hemikaliju (Tabela1)

- Nijedan deo biljke ne mora sadržati neku hemikaliju jer se npr. ona ne proizvodi do određenog perioda rasta (nestabilna ulja mogu se ekstrahovati u ranom periodu cvetanja i nakon tog perioda se postepeno gube). regiji.

Table 1. Distinctive plant parts, some selected plants

Tabela 1. Određeni delovi biljaka, neke odabrane biljke

\begin{tabular}{|l|l|l|}
\hline Plant part & Selected plant & Reciprocal word in English \\
\hline Bulbus & bulbus scillae (Drimia species) & Onion \\
\hline Cera & cera flava (Beewax) & Wax \\
\hline Cortex & cortex cinnamoni (Cinnamon) & Bark \\
\hline Flos & flos tiliae (Linden) & Flower \\
\hline Folium & folium althacea (Marshmallow) & Leave \\
\hline Fructus & fructus lauri (Bay) & Fruit \\
\hline Gummi & gummi tragacanthae (Juice of astragalus root) & Gum \\
\hline Herba & herba artemisiae (Wormwood) & Weed, herb \\
\hline Lignum & lignum juniperi (Juniper) & Wood \\
\hline Oleum & oleum amigdalae (Almond) & Oil \\
\hline Olea aetherae & oleum amigdalae eatherum (Almond) & Volatile oil \\
\hline Olea fixa & oleum amigdalae-(Almond) & Fixed oil \\
\hline
\end{tabular}


(a)

\begin{tabular}{|l|l|l|}
\hline Pix & pix juniperi (Juniper) & Tar \\
\hline Radix & radix liquiritiea (Licorice) & Root \\
\hline Resina & recina pini (Pine) & Rosin \\
\hline Rhisoma & rhizoma graminiz (Couch grass) & Rhizome \\
\hline Semen & semen lini (Linen) & Seed \\
\hline Succus & succus citri (Lemon) & Water \\
\hline Tubera & tubera salep (Sahlep) & Tuber \\
\hline
\end{tabular}

\section{Achillea millefolium (Yarrow):}

The essential oil of Achillea millefolium has antimicrobial effects, the sesquiterpenes have antiphlogistic activity, dicaffeoylquinic acids (DCQAs) have choleretic effects, and the flavonoids have spasmolytic activit ${ }^{11}$, (Figure 1).

Figure 1. Achillea millefolium (Yarrow)

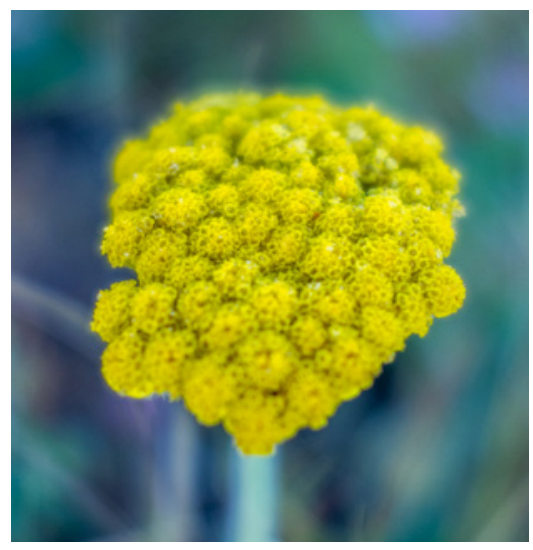

\section{Achillea millefolium (Hajdučka trava)}

Esencijalno ulje Achillea millefolium ima antimikrobno dejstvo, seskviterpeni imaju antiflogističko dejstvo, dikafeoilkvinične kiseline imaju holeretičke efekte, a flavonoidi imaju spazmolitičko dejstvo $^{11}$, (Slika 1).

Slika 1. Achillea millefolium (Hajdučka trava)

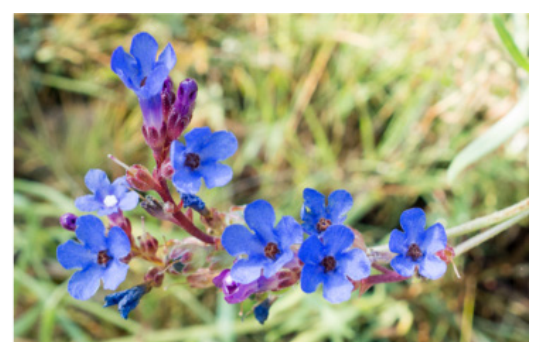

\section{Anchusa leptophylla:}

Anchusa je iz porodice Boragineae i sadrži fenolične komponente. Metabolički efekti ovih sastojaka povezani su sa antioksidativnim, antiaterosklerotskim, antizapaljenskim dejstvo ${ }^{12}$, (Slika 2).

Slika 2. Anchusa leptophylla

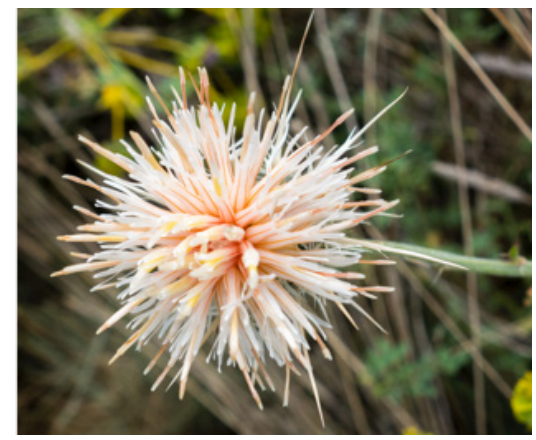

\section{Asphodelus albus (Zlatoglav):}

Korenovi Asphodelus species imaju antrakinon derivate (krisofanol, aloja-emodin, triterpenoide i naftalen). Njegovi delovi koji se nalaze iznad zemlje imaju flavonoide. Oni imaju antiinflamatorno, antifungalno, antibakterijsko i antioksidativno dejstvo ${ }^{13}$, (Slika 3).

Slika 3. Asphodelus albus (Zlatoglav) 


\section{Cychorium inthybus (Chicory):}

This plant contains inulin and its metabolic effects can be listed as diuretic, anti-inflammatory, anti-oxidative and immunomodulating ${ }^{14}$, (Figure 4).

Figure 4. Cychorium inthybus (Chicory)

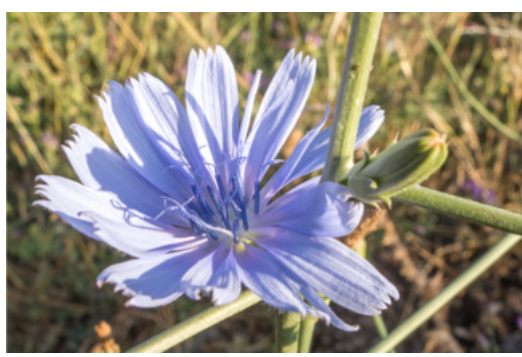

\section{Cychorium inthybus (Cikorija):}

Ova biljka sadrži inulin a njena metabolička dejstva su diuretsko, antiinflamatorno, antioksidativno i imunomodulatorno ${ }^{14}$, (Slika 4).

Slika 4. Cychorium inthybus (Cikorija)

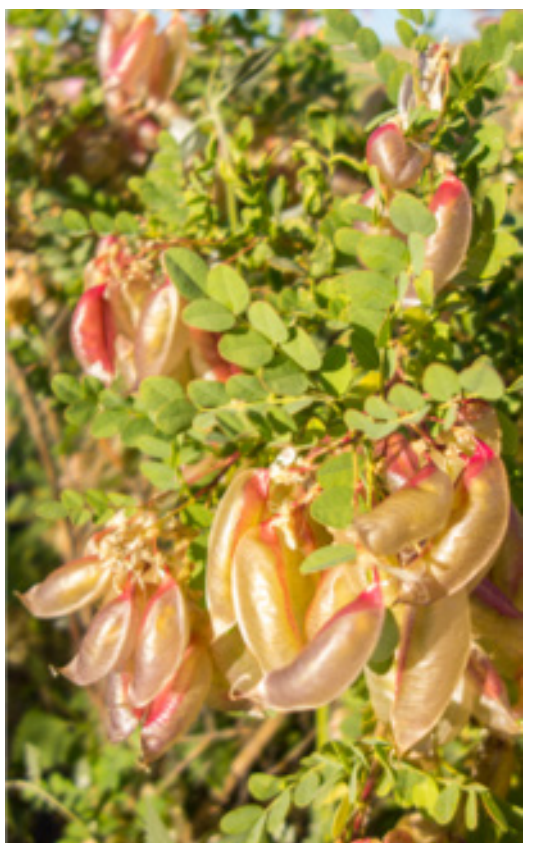

\section{Helleborus vesicarius (Kukurek):}

Helleborus Vesicarius contains saponoides. A phytosterol called g-sitosterol is cardioactive and has suppressive and diuretic characteristics ${ }^{\ddagger 5}$, (Figure 5).

Figure 5. Helleborus vesicarius (Hellebores)

\section{Hyocymus niger (Henbane):}

It is a well known alkaloid (hyosiyamin, atropin, skopolamin) and its metabolic effects are commonly toxic effect ${ }^{16}$. (Figure 6).

Figure 6. Hyocymus niger (Henbane)

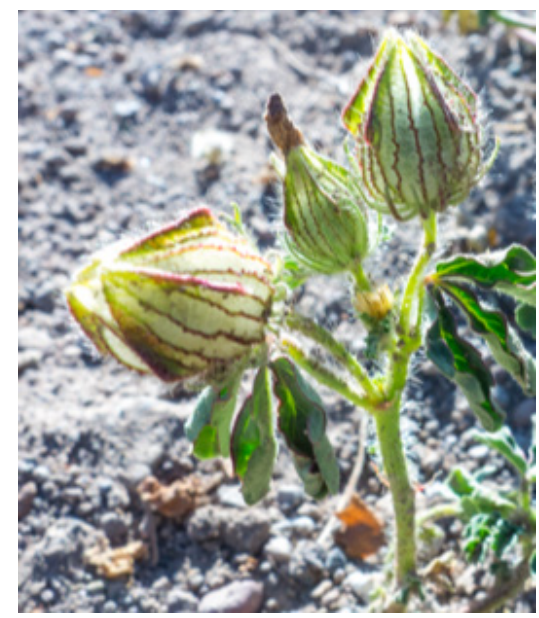

\section{Hyocymus niger (Henbane):}

To je dobro poznati alkaloid (hiosiamin, atropin, skopolamin) i njegovi metabolički efekti su obično toksični ${ }^{16}$, (Slika 6).

Slika 6. Hyocymus niger (Henbane) 


\section{Spices}

They are not food, but are used to give special taste, in addition to foods ' natural taste. Spices are parts of plants which have got special taste or they may interfere with the digestion of foods, in order for anybody to feel good, relaxed or avoid unpleasant side effects of foods. Allium cepa (onion), allium sativum (garlic), thymus vulgaris (thyme), mentha longifolia (horse mint), piper nigrum (black pepper), capsicum (red pepper) can be listed as frequently used spices. Although spices are also plant parts, according to their use we may classify them as:

- Insect repellents (Fenugreek seed extract-Tribolium castaneum)

- Antimicrobials (Spearmint, basil, parsley oilStaphylococcus aureus, Escherichia coli Candida albicans, Aspergillus niger)

- Antioxidants (Red pepper-Capsaicin)

- Used in alcoholic beverages (Gin-Coriander, juniper berry)

- Used with foods (Flavoring-parsley, cinnamon, deodorizing-thyme, rosemary

- Pungency-ginger, horseradish, red pepper, colouring-turmeric, saffron)

Use of spices with foods may not be intended as a drug or health improver, but other uses are smilar to plant phytochemical's use in certain disorders.

\section{Toxicity of plant chemicals}

Plants can be toxic to humans and toxic phytochemicals can be used as drugs in humans ${ }^{17}$.

Poisonous plants can be grouped as ${ }^{18}$;

- Home plants: Hyacinthus orientalis, Narcissus, cerium oleander,

- Garden flowers: Delphinium, Aconitum species, colchicum autumnal,

- Vegetables: Solanum nigrum, rheum rhaponticum,

- Ornamental plants: Daphne, Wisteria, Calmina species,

- Wild plants: Sambucus species, Sanguinaria Canadensis, Podophyllum peltatum.

\section{Začini}

Začini nisu hrana, ali se koriste u ishrani kako bi poboljšali ukus hrane. Začini su delovi biljaka koji imaju poseban ukus ili mogu uticati na varenje hrane, i koriste se da bi se čovek osećao dobro, opušteno i kako bi se izbegla neprijatna neželjena dejstva nekih vrsta hrane. Allium cepa (crni luk), allium sativum (beli luk), thymus vulgaris (majčina dušica), mentha longifolia (divlja nana), piper nigrum (crni biber), capsicum (ljute paprike) su neki od najčešće korišćenih začina. Iako su začini delovi biljaka, prema njihovoj upotrebi možemo ih klasifikovati na:

- Sredstva protiv insekata (ekstrakt grčke detelineTribolium castaneum)

- Začini sa antimikrobnim dejstvom (nana, bosiljak, peršunovo ulje, Staphylococcus aureus, Escherichia coli, Candida albicans, Aspergillus niger)

- Antioksidansi (ljute paprike-Capsaicin)

- Upotreba u alkoholnim pićima (Džin-korijander, kleka)

- Korišćeni sa hranom (ukus-peršun, cimet; mirismajčina dušica, ruzmarin)

- Začini oštrih ukusa (đumbir, ren, papričice, davanje boje-kurkuma, šafran)

Upotreba začina u ishrani možda nema uvek za cilj da bude lek ili poboljša zdravlje, ali je njihovo korišćenje slično upotrebi biljnih hemikalija kod određenih bolesti.

\section{Toksičnost biljnih hemikalija}

Biljke mogu biti toksične za ljude i toksične fitohemikalije mogu se koristiti kao lekovi u humanoj medicini ${ }^{17}$.

Otrovne biljke mogu se grupisati $\mathrm{kao}^{18}$

- Kućne biljke: Hyacinthus orientalis, Narcis, cerium oleander

- Baštensko cveće: Delphinium, Aconitum species, colchicium autumnal

- Povrće: Solanum nigrum, rheum rhaponticum

- Ukrasne biljke: Lovorika, glicinija, calmina species

- Divlje biljke: Sambucus species, Sanguinaria Candensis, Podophyllum peltatum 


\section{Conclusion}

\section{Zaključak}

A famous quote by French writer François Marie Arouet (Voltaire) describes physicians: "Doctors are men who prescribe medicines of which they know little, to cure diseases of which they know less, to human beings of whom they know nothing". This statement may be an excellent description of the pattern of physician-patient relationship. Physicans ' motivation of "intention to treat" can not be considered as bad faith of physicians. Neither use of pharmaceutical drugs nor plants, as therapeutic tools, is different intervention. Dose, duration of therapy, way of application, interaction with foods or other drugs is principally identical, both in pharmaceutical drugs and phytoherapeutic remedies.

Contrary to similarities between pharmaceutical drugs and phytotherapeutic remedies, chemicals in plants have different concentration of chemicals in different parts of the plant: onion, leave, flower, root, etc. Even in any part of a plant the concentration of phytochemical cannot be predicted. Sometimes edible, phytotherapeutic and poisonous plants may be very similar or even may be considered identical. As a conclusion we may say that detailed, botanical and pharmacognostic information, education and practice that is accredited by an official institution is essential. In addition to this initial requirement, the variability of phytochemical concentration should limit physician's prescription behaviours, so it's advisable to start with minimal dose, frequent check-ups for adverse effects and gradual use of plants as remedies in daily medical practice.

Poznati citat francuskog pisca Fransoa Mari Arua (Volter) opisuje lekare: "Lekari su ljudi koji propisuju lekove o kojima malo znaju, da bi lečili bolesti o kojima znaju još manje, ljudima koje ne poznaju uopšte." Ova izjava može biti dobar opis obrasca odnosa između lekara i pacijenta. Lekarska motivacija "namera da se leči” ne može se smatrati lošom namerom lekara. Farmakološki lekovi i biljke se podjednako koriste u lečenju. Doziranje, vreme trajanja lečenja, način primene, interreakcije sa hranom ili drugim lekovima je u principu identična sa farmakološkim lekovima.

Uprkos sličnosti između farmaceutskih i fitoterapijskih lekova, hemikalije u biljkama imaju različite koncentracije hemikalija u različitim delovima biljaka: lukovica, list, cvet, koren itd. Koncentracija fitohemikalije ne može se predvideti ni u jednom delu biljke. Ponekad jestive, fitoterapijske i otrovne biljke mogu biti vrlo slične, gotovo identične. U zaključku možemo reći da su detaljne botaničke i farmakognostičke informacije, usavršavanje i praksa od strane oficijelnih institucija najbitniji. Uz ovo, lekar mora biti na oprezu kada ih preporučuje zbog varijabilnost koncentracije fitohemikali$\mathrm{ja}$, te se zato preporučuje da se počne sa minimalnom dozom, češčim proverama sporednih efekata i postepenim povećanjem doze kada se biljke koriste kao lekovi u svakodnevnoj medicinskoj praksi. 


\section{Literatura / Reference}

1. Mazıcıoğlu MM, Serin İS, Şahan H. Attitude of patients with gynecologic malignancies in selecting alternative and complementary therapies. Middle East Journal of Family Medicine, 2006;4(2): $12-15$.

2. Aydın S, Bozkaya AO, Mazicioglu MM, Gemalmaz A, Ozcakir A, Ozturk A. What Influences Herbal Medicine Use? Prevalence and Related Factors. Turk J Med Sci, 2008;38(5):455-463.

3. Öztürk H, Mısırlığlu N, Mazıcığlu MM Akılcı İlaç Tedavisine Uyumu Etkileyen Faktörler ve Uyumu Artırıcı çözüm Önerileri. Turkiye Klinikleri J Fam MedSpecial Topics 2017;8(3):176-82,

4. Ozçakır A, Sadıkoglu G, Bayram GN, Mazıcıoğl, MM, Bilgel N, Beyhan I. Turkish. Genral Practitioners and Complementary / Alternative Medicine. J Altern Comment Mepled. .2007;13(9):1007-1010.

5. CAM 2020; The contribution of Complementary and Alternative Medicine to sustainable healthcare in Europe http:// www.camdoc.eu/Pdf/CAM $\% 202020 \% 20$ final.pdf. reached at 26.04.2020

6. Mazıcıŏlu MM. Akupunktur tedavisinin gelişim süreci türleri ve metodolojisi. Türkiye klinikleri Aile hekimliği özel say1s1. 2014;5(4):28-34.
7. El Dib RP, Atallah AN, Andriolo RB. Mapping the Cochrane evidence for decision making in health care. Journal of Evaluation in Clinical Practice, 2007;13:689-692.

8. Petrovska BB. Historical review of medicinal plants' usage. Pharmacogn Rev. 2012 Jan-Jun;6(11):1-5.

9. The constitutes of medicinal plants; An introduction to the chemistry and therapeutics of herbal medicine. Second Ed. Singapore 2004; pp 1-13.

10. Benedek B, Rothwangl-Wiltschnigg K, Rozema E, Gjoncaj N, Reznicek G, Jurenitsch J, Kopp B, Glasl S. Yarrow (Achillea millefolium L. s.1.): Pharmaceutical quality of commercial samples. Pharmazie 2008;63: 23-26.

11. Kuruüzüm-Uz A, Güvenalp Z, Kaza C , Demirezer LÖ. Phenolic compounds from the roots of Anchusa azurea var. azurea. Turk J Pharm Sci 2013;10(2):177-184, .

12. Malmir M, Serrano R, Caniça M, SilvaLima B, Olga Silva O. A Comprehensive Review on the Medicinal Plants from the Genus Asphodelus Plants 2018;7:20.
13. Street RA, Sidana,J, Prinsloo G. Cichorium intybus: Traditional Uses, Phytochemistry. Pharmacology, and Toxicology Evidence-Based Complementary and Alternative Medicine 2013;1:13.

14. Bingöl. F, Sener B. Pharmacognosic researches on Helleborus vesicarious. Auch. J. Fac. Pharm. Gazi 1986;3(2): 95-98.

15. Yucel UM, Yılmaz O. Van Yöresinde Yetișen İki Hyoscyamus (Banotu) Türünün Total Alkaloid Miktarları. YYU Veteriner Fakultesi Dergisi 2014; 25 (3):77-80.

16. Amilselvan N, Thirumalai T, Shyamala P, David E. A review on some poisonous plants and their medicinal values. Journal of Acute Disease 2014: 85-89.

17. Kingsbury JM. Common poisonous plants. Bulletin 104 A Cornell Cooperative Extension Publication 1994;pp 4-15.

Autori izjavljuju da nemaju sukob interesa Conflict of Interest: None declared

Primljen - Received 27.4.2020.

Ispravljen - Corrected -

Prihvaćen - Accepted 10.6.2020. 